\title{
El Artículo 422 de la Constitución y su Incidencia en el Arbitraje Internacional
}

\author{
Mario Alejandro Flor
}

\section{Sumario}

1. Introducción. 2. Los artículos constitucionales relativos a arbitraje del sector público, ¿existe contradicción? 3. Similitudes con otras norma jurídicas que se refieren al sometimiento a jurisdicción distinta de la ecuatoriana. 4. Conclusiones.

\section{INTRODUCCIÓN}

La nueva Constitución de la República del Ecuador, promulgada en el año 20081, reconoce al arbitraje, la mediación y otros procedimientos alternativos para la solución de conflictos. En lo que tiene que ver con el arbitraje en general y el arbitraje del sector público en particular, dice el artículo 190 de la Constitución lo siguiente:

"Se reconoce el arbitraje, la mediación y otros procedimientos alternativos para la solución de conflictos. Estos procedimientos se aplicarán con sujeción a la ley, en materias en las que por su naturaleza se pueda transigir.

En la contratación pública procederá el arbitraje en derecho, previo pronunciamiento favorable de la Procuraduría General del Estado, conforme a las condiciones establecidas en la ley."

1. Constitución de la República del Ecuador (vigente). Publicada en el Registro Oficial 499 de 20 de Octubre de 2008. 
Por su parte, el artículo 422 de la Constitución del 2008, al referirse a las limitaciones a la celebración de tratados o instrumentos internacionales, señala lo siguiente:

"No se podrá celebrar tratados o instrumentos internacionales en los que el Estado ecuatoriano ceda jurisdicción soberana a instancias de arbitraje internacional, en controversias contractuales o de índole comercial, entre el Estado y personas naturales o jurídicas privadas.

Se exceptúan los tratados e instrumentos internacionales que establezcan la solución de controversias entre Estados y ciudadanos en Latinoamérica por instancias arbitrales regionales o por órganos jurisdiccionales de designación de los países signatarios. No podrán intervenir jueces de los Estados que como tales o sus nacionales sean parte de la controversia

En el caso de controversias relacionadas con la deuda externa, el Estado ecuatoriano promoverá soluciones arbitrales en función del origen de la deuda y con sujeción a los principios de transparencia, equidad y justicia internacional"

Como consecuencia de la promulgación de la Constitución del 2008, a inicios del año 2010, el Presidente de la República solicitó a la Corte Constitucional emita un dictamen favorable para la denuncia de trece acuerdos bilaterales de Protección Recíproca de Inversiones (TBIs) -con Finlandia, Suecia, Canadá, China, Países Bajos, Alemania, Francia, Reino Unido e Irlanda, Chile, Venezuela, Suiza y Estados Unidos de América-, ello como un paso previo para que la Asamblea Nacional proceda a dar trámite a la aprobación de dicha denuncia de conformidad con lo dispuesto por el numeral 7 del artículo 419 de la Constitución y del 4 del artículo 112 de la Ley Orgánica de Garantias Constitucionales y Control Constitucional. Dicha solicitud va de la mano con la denuncia y terminación del Convenio sobre Arreglo de Diferencias relativas a Inversiones entre Estados y nacionales de otros Estados -CIADI_-2 ejecutada

2. El Convenio sobre Arreglo de Diferencias relativas a Inversiones entre Estados y nacionales de otros Estados entró en vigencia en Ecuador al expedirse el Decreto Ejecutivo 1417-B de 6 de abril de 2001 con el que se ratifico dicho convenio. 
mediante Decreto Ejecutivo No. 1823 expedido por el Presidente de la República el 2 de Julio de 2009.

La Corte Constitucional, a mediados del año 2010 dictaminó favorablemente para continuar con dicho trámite de denuncia de ciertos convenios, por considerar que los artículos relacionados con el sometimiento del Estado ecuatoriano al arbitraje internacional para la solución de conflictos, contenidos en varios TBIs suscritos por el Ecuador, van en desmedro del artículo 422 de la Constitución.

\section{LOS ARTÍCULOS CONSTITUCIONALES RELATIVOS A ARBITRAJE DEL SECTOR PÚBLICO, ¿EXISTE CONTRA- DICCIÓN?}

La solicitud de denuncia de los TBIs y las decisiones de la Corte Constitucional antes referidas ciertamente buscan evitar que el Estado ecuatoriano continúe sometido a la resolución de las diferencias provenientes de inversiones extranjeras a instancias de arbitraje internacional.

Dichos TBIs se constituyeron, en las últimas décadas, en instrumentos del Derecho Internacional destinados a promover flujos internacionales de capital mediante el establecimiento de ciertas protecciones a fin de mitigar riesgos políticos cuando inversionistas internacionales hacen negocios en países distintos a su país de origen. La Corte Constitucional, al hacer el análisis de constitucionalidad de varios de estos convenios, consideró que los mismos constituyen un tipo especial de contrato suscrito entre dos Estados para asegurar una efectiva protección al inversionista extranjero por parte del Estado receptor, que en la práctica ha significado que los beneficios vayan en gran medida a los países inversionistas o de origen de capital. Es interesante, sin embargo, que por una parte, no se haya presentado -al menos hasta donde yo conozco- una solicitud de denuncia de 
convenios bilaterales con otros países que contendrían cláusulas similares a las analizadas por la Corte Constitucional en sus recientes dictámenes, y por otra, que el Estado ecuatoriano continúe reconociendo y suscribiendo cláusulas arbitrales internacionales en contratos suscritos con inversionistas, algunos de los cuales no tienen origen latinoamericano.

Por ello, surgen algunas preguntas: ¿Existe contradicción entre los artículos 190 y 422 de la Constitución? ¿Quiere esto decir que el Estado ecuatoriano reconoce el arbitraje del sector público, pero cuando se trate de controversias contractuales o de índole comercial de las que sea parte el Estado, únicamente podrá acordar arbitraje local o a lo sumo arbitraje regional, y en este último caso para dar solución a controversias entre Estados y ciudadanos de Latinoamérica? ¿Qué ocurre con las controversias con ciudadanos y empresas de otros países del mundo con los que el Ecuador tiene relaciones comerciales?

Para intentar contestar a estas preguntas, comencemos con un análisis más detallado del artículo 422 de la Constitución:

En el primer inciso la Carta Magna expresa que no se podrá celebrar ningún tipo de tratado o convenio internacional mediante el cual el Estado ecuatoriano ceda jurisdicción soberana a instancias de arbitraje internacional en controversias de índole comercial o contractual. Por lo tanto, este inciso se limita a establecer que será inconstitucional todo convenio o tratado internacional por el que el Estado ceda la jurisdicción soberana, afectando de este modo la soberanía territorial y que se refiere a la administración de justicia por tribunales del Estado, a instancias de arbitraje internacional en conflictos contractuales o comerciales, que se susciten con personas naturales o jurídicas privadas.

El segundo inciso, expresa que se exceptúan de lo dispuesto en el primer inciso ya mencionado, aquellos tratados e instrumentos internacionales que establezcan la jurisdicción arbitral para solucionar conflictos que surjan entre el Estado ecuatoriano 
y ciudadanos latinoamericanos. En dicho caso, estos tratados deberán contemplar una jurisdicción arbitral regional. No queda claro, sin embargo, si dentro del término "ciudadanos en Latinoamérica" quedan incluidas personas jurídicas creadas al amparo de las legislaciones de los países latinoamericanos.

El tercer inciso del artículo expresa claramente que el Estado ecuatoriano "promoverá", dentro de controversias relacionadas a deuda externa, soluciones arbitrales en relación al origen de la deuda, y en relación a los principios de equidad, transparencia y justicia internacional.

Mis comentarios sobre dicho texto, a continuación:

(i) El primer párrafo del artículo 422 de la Constitución de la República establece que "No se podrá celebrar tratados o instrumentos internacionales en los que el Estado ecuatoriano ceda jurisdicción soberana a instancias de arbitraje internacional, en controversias contractuales o de índole comercial, entre el Estado y personas naturales o jurídicas privadas". Aunque no existe una definición en la legislación ecuatoriana para el término "instrumento internacional", deberemos entender que este término se refiere precisamente a los acuerdos internacionales suscritos por el Estado con otros Estados, gobernados por el derecho internacional (siguiendo la definición de tratado establecida en la Convención de Viena sobre los Tratados). Tal es el caso de los TBIs.

(ii) En este contexto, cabe señalar que el artículo 422 de la Constitución se encuentra en el Capítulo II "Tratados e Instrumentos Internacionales" del Título VIII "Relaciones Internacionales". Dicho capítulo se refiere básicamente a los tratados ratificados por Ecuador y a la necesidad de que éstos se encuentren sujetos a la Constitución. Tengamos en cuenta que el primer párrafo del artículo 418, que también se encuentra en el mismo 
capítulo, establece que, en su calidad de representante del Estado, el Presidente de la República es competente para firmar o ratificar los tratados internacionales y otros instrumentos internacionales y el artículo 419 establece en qué casos la ratificación o denuncia de dichos tratados requerirá la aprobación previa de la Asamblea Nacional. Claramente estos artículos constitucionales se refieren a los convenios suscritos por el Estado con otros Estados y regidos por el derecho internacional.

(iii) El artículo 422 de la Constitución busca rechazar los tratados y convenios internacionales en los que el Ecuador ceda jurisdicción soberana a instancias arbitrales internacionales, es decir que el Estado no podría, mediante la celebración de un tratado internacional, dejar de reconocer la facultad de administrar justicia por parte de los tribunales y cortes ecuatorianos en beneficio de una jurisdicción arbitral internacional en controversias contractuales o comerciales con personas naturales o jurídicas privadas. A mi modo de ver, este texto evidencia la posición de Ecuador, como Estado soberano, de no suscribir convenios internacionales en los que el Gobierno anticipada e indiscriminadamente otorgue un consentimiento general para someter cualquier diferencia de carácter contractual o comercial a arbitraje internacional, en detrimento de la jurisdicción local. La razón detrás de esto, como yo lo veo, es que los TBIs suscritos antes de la entrada en vigencia de la nueva Constitución, son convenios internacionales por los que el Ecuador hizo una renuncia a priori a su jurisdicción soberana a favor de tribunales arbitrales internacionales, sin el beneficio de discutir con el inversionista extranjero los términos y condiciones en cada caso y sin conocer de antemano cuáles son los asuntos específicos que se someterán a arbitraje, constituyéndose así en una suerte de cláusula compromisoria general, o por lo menos una oferta arbitral unilateral e irrevocable, pero sujeta a la elección y aceptación 
del inversionista extranjero-. Esto, que según la Corte Constitucional, no transgredía ninguna norma constitucional cuando se encontraban vigentes las Constituciones de 19793 codificada en 1993 y la de $1998^{4}$, contraviene el actual texto constitucional.

(iv) No considero que los contratos de inversión u otros instrumentos contractuales puedan considerarse incluidos en el término "instrumentos internacionales" según lo referido en el artículo 422. El Estado ecuatoriano ha suscrito y es parte de diferentes tipos de contratos con personas naturales y jurídicas privadas (por ejemplo: contratos de concesión de servicios públicos, contratos de explotación de recursos naturales, contratos de ejecución de obras públicas, etc.) que no podrían ser considerados "instrumentos internacionales" en el sentido al que se refiere el artículo 422, por el solo hecho de que la contraparte del Estado en dichos contratos sea un inversionista internacional.

(v) No olvidemos que el arbitraje internacional se encuentrareconocido en la legislación local y continua siendo un mecanismo alternativo de solución de controversias.

El Artículo 41 de la Ley de Arbitraje y Mediación ${ }^{5}$ se refiere expresamente a este tema cuando señala:

"Sin perjuicio de lo dispuesto en los tratados internacionales un arbitraje podrá ser internacional cuando las partes así lo hubieren pactado, siempre y cuando se cumplan cualquiera de los siguientes requisitos:

a) Que las partes al momento de la celebración del convenio arbitral, tengan sus domicilios en estados diferentes;

3. Constitución Politica de la República del Ecuador (derogada), publicada en el Registro Oficial No. 800 de 27 de marzo de 1979.

4. Constitución Politica de la República del Ecuador (derogada), publicada en el Registro Oficial No. I de 11 de Agosto de 1998.

5. Ley de Arbitraje y Mediación, publicada en el Registro Oficial No, 145 del 4 de Septiembre de 1997. 
b) Cuando el lugar de cumplimiento de una parte sustancial de las obligaciones o el lugar en el cual el objeto del litigio tenga una relación más estrecha, esté situado fuera del estado en que, por lo menos una de las partes, tiene su domicilio; 0 ,

c) Cuando el objeto del litigio se refiera a una operación de comercio internacional que sea susceptible de transacción y que no afecte o lesione los intereses nacionales o de la colectividad."

Por su parte el Artículo 42 de la mencionada Ley, establece que

"El arbitraje internacional quedará regulado por los tratados, convenciones, protocolos y demás actos de derecho internacional suscritos y ratificados por el Ecuador.

Toda persona natural o jurídica, pública o privada, sin restricción alguna es libre de estipular directamente o mediante referencia a un reglamento de arbitraje todo lo concerniente al procedimiento arbitral, incluyendo la constitución, la tramitación, el idioma, la legislación aplicable, la jurisdicción y la sede del tribunal, la cual podrá estar en el Ecuador o en país extranjero.

Para que el Estado o las instituciones del sector público puedan someterse al arbitraje internacional se estará a lo dispuesto en la Constitución y leyes de la República.

Para que las diferentes entidades que conforman el sector público puedan someterse al arbitraje internacional se requerirá la autorización expresa de la máxima autoridad de la institución respectiva, previo el informe favorable del Procurador General del Estado, salvo que el arbitraje estuviere previsto en instrumentos internacionales vigentes. 
Los laudos dictados dentro de un procedimiento de arbitraje internacional, tendrán los mismos efectos y serán ejecutados de la misma forma que los laudos dictados en un procedimiento de arbitraje nacional."

El arbitraje es una institución de origen contractual, las partes pueden ellas mismas acordar las reglas de procedimiento, delegar esta función a los árbitros designados o someterlas a las reglas y procedimientos de la institución arbitral que hayan escogido. Bajo esta perspectiva, las normas jurídicas antes citadas permiten que el Estado exprese su consentimiento a dichos arbitrajes internacionales en casos específicos, sin que ello, a mi modo de ver, implique una cesión o renuncia a jurisdicción soberana.

(vi) El principio general que rige el arbitraje sigue siendo el mismo: todo asunto en el que se pueda transigir es un asunto que puede ser sometido a arbitraje, lo cual se encuentra recogido en el artículo 190 de la Constitución y en el artículo 4 de la Ley de Arbitraje y Mediación. El Estado no se encuentra excluido de la posibilidad de pactar arbitraje, tanto local como internacional y hasta arbitraje extranjero, previo cumplimiento de las formalidades y requisitos previstos en la Constitución y la ley.

\section{Similitudes CON Otras NORMas JURídicas QUE SE REFIEREN AL SOMETIMIENTO A JURISDICCIÓN DISTIN-} TA DE LA ECUATORIANA

El artículo 14 de la Constitución Política del Ecuador que estuvo vigente desde el año 1998 hasta el año 2008, establecía que aquellos contratos celebrados entre la República del Ecuador con personas naturales o jurídicas extranjeras, dentro del territorio ecuatoriano, no podían sujetarse a una jurisdicción diferente a la ecuatoriana salvo que exista un convenio internacional. 
Por lo tanto, solamente se podían someter a una jurisdicción extraña a la ecuatoriana, aquellos contratos que se celebraban fuera de la República del Ecuador.

A la luz de las disposiciones vigentes a la fecha, cabe hacer una breve diferenciación de carácter conceptual.

En primer lugar, la reclamación diplomática mencionada en la actual Constitución (que igualmente estaba referida en la anterior Constitución), y en el artículo 128 del Código Orgánico de Planificación y Finanzas Públicas, se refiere a un acto de gobierno mediante el cual determinado Estado -o eventualmente un sujeto de Derecho Internacional Público en general- reclama por los intereses de un nacional frente a otro Estado u otro sujeto de Derecho Internacional. Manuel Diez de Velasco la define como "...la acción que ejerce un sujeto de Derecho Internacional - de estructura estatal o no - respecto a otro sujeto de Derecho Internacional a favor de ciertos individuos que tiene ligánenes por el."6

El artículo 307 de la actual Constitución expresa:

"Los contratos celebrados por el Estado con personas naturales o juridicas extranjeras llevarán implícita la renuncin de éstas a toda reclamación diplomática, salvo contrataciones que correspondan al servicio diplomático."

El artículo 128 del Código Orgánico de Planificación Y Finanzas Públicas, expedido en el $2010^{7}$, expresa:

"Renuncia a reclamación diplomática.- Todo contrato o convenio de deuda pública, celebrado por extranjeros domiciliados o no en el país, sean personas naturales o jurídicas, con la República del Ecuador o con las demás entidades del sector público, lleva implícito la condición de renuncia a toda

6. Manuc! Dicz de Velasco. Instituciones de Derecho Intemacional Público. Tomo 1. Editorial Tecnos. Madrid, 1976, p. 334.

7. Código Orgánico de Planificaciỏn y Finanzas Públicas, publicado en el Registro Oficial Suplemento- No. 306 de fecha 22 de octubre de 2010. 
reclamación por vía diplomática, aunque se suscriban fuera del territorio ecuatoriano."

Ambas normas señalan que todo contrato o convenio celebrado con una entidad extranjera, dentro o fuera del territorio ecuatoriano, lleva implícita la condición de renuncia a toda reclamación diplomática. Los citados artículos nada dicen respecto de la prohibición de sometimiento a jurisdicción extraña; aquellas disposiciones referentes a la jurisdicción aplicable a ciertos actos o contratos celebrados entre sujetos de Derecho Público, las cuales son normas de carácter jurídico administrativo, se rigen por normas y acuerdos específicos que regulan la jurisdicción de dichos actos o contratos.

A este respecto, el artículo 141 del Código Orgánico de Planificación y Finanzas Públicas, señala que:

"De conformidad con los principios de soberanía y los derechos previstos en la Constitución de la República, en las operaciones de endeudamiento público externo, se observarán y aplicarán las condiciones legales propias de los contratos negociados bajo la ley y jurisdicción internacional."

Adicionalmente, la Disposición General Quinta del Código Orgánico de Planificación y Finanzas Públicas ordena:

"Autorización Previa.- Previa autorización por el Procurador General del Estado, podrá aceptarse otra jurisdicción y legislación para la solución de divergencias o controversias relativas a contratos, celebrados por el Estado y las entidades y organismos del sector público con gobiernos, entidades públicas o privadas extranjeras."

Como vemos, el artículo 141 del Código Orgánico De Planificación y Finanzas Públicas señala que el Estado deberá observar y aplicar al momento de realizar operaciones de crédito externo, las condiciones legales propias de los contratos negociados bajo la ley y jurisdicción internacional. 
Por su parte, la Disposición General Quinta del Código Orgánico de Planificación y Finanzas Públicas expresa que previa autorización del Procurador General del Estado, podrá el Estado y otras entidades de derecho público someterse a otra jurisdicción y legislación para la solución de controversias relacionadas a contratos celebrados con entidades públicas o privadas extranjeras, reconociendo así a dichas jurisdicciones y legislaciones, a las cuales, eventualmente puede someterse el Estado.

Por tanto, el Ecuador puede someterse a jurisdicción y ley internacionales cuando celebra contratos celebrados con entidades públicas o privadas extranjeras, previa autorización del Procurador General del Estado, sin que siquiera se mantenga la necesidad de suscribir dicho contrato fuera del país como lo señalaba antes, de forma expresa, el artículo 14 de la Constitución de 1998. Que tanto dista este sometimiento de aquel contenido en una cláusula en que el Estado se comprometa a someterse a arbitraje internacional en un contrato suscrito con personas naturales o jurídicas privadas?

\section{Conclusiones}

Una cláusula compromisoria en la que el Estado ecuatoriano pacte arbitraje extranjero o internacional, similar a una en que pacte el sometimiento a ley y jurisdicción extranjera para la solución de controversias nacidas de un determinado contrato, no implica una renuncia a la "Jurisdicción del Estado", como una de las manifestaciones de la soberanía territorial. El poder de administrar justicia por parte de los tribunales del Estado ecuatoriano no se ve disminuido por el hecho de que un determinado caso sea sometido a arbitraje, conforme a las disposiciones de la legislación Jocal, que además se encuentran respaldadas por el artículo 190 de la Constitución que reconoce el arbitraje como un mecanismo para resolver controversias. 
Los artículos 190 y 422 de la Constitución no se contradicen; el Estado ecuatoriano puede continuar accediendo a arbitraje local e internacional, en materia de controversias contractuales y de índole comercial, mediante cláusulas compromisorias suscritas en los respectivos contratos, o mediante acuerdos arbitrales independientes, y sometiéndose a reglas y procedimientos de instituciones arbitrales internacionales. No puede el Estado, sin embargo desconocer la jurisdicción de jueces, tribunales y cortes ecuatorianas para la resolución de controversias contractuales o de índole comercial que surjan entre el Estado y personas naturales o jurídicas privadas, mediante la suscripción de tratados y convenios internacionales, tal como lo señala el artículo 422 de la Constitución vigente.

El sometimiento a jueces y tribunales extranjeros, así como a jueces y tribunales arbitrales, y la sujeción a ley extranjera en los casos que amerite dicho sometimiento, no se encuentra prohibido por la legislación ecuatoriana. Por el contrario, se encuentra permitido y regulado.El arbitraje internacional sigue siendo, por tanto, un mecanismo válido e idóneo para resolución de controversias entre el Estado y personas naturales y jurídicas privadas.

Diciembre de 2011. 